\title{
It Has Been a Hard Day's Year
}

\author{
Helena Canhão \\ NOVA Medical School, NOVA University Lisbon, Lisbon, Portugal
}

2021 has come to an end. And the pandemic remains among us. But things are much better. Even though new variants emerged, and the number of cases is still very high, with vaccination and other public policy measures, the severity and the number of deaths are much lower. The investment in science, medicine, resources, health care systems and public health, in general, is key to the appropriate response to the emerging challenges that populations are facing.

The Portuguese Journal of Public Health is well reputed, receiving an increased number of paper submissions, focused on disseminating peer-reviewed high-quality papers.

In this number (of course), COVID is debated. Manuela Hoedl et al. assessed "COVID-19 among nursing staff: settings and regional differences," while Héloïse Lucaccioni Duque et al. assessed "Risk of COVID-19 in health professionals: a case-control study, Portugal" and Diana Portela reported "Using digital technologies in response to the COVID-19 pandemic in Portugal."

We would also like to highlight other very important subjects related to public health. One of them is patient safety. This topic is increasingly attracting attention, in a patient-centered system. The WHO supports a Global Patient Safety Action Plan, and Paulo Sousa et al. are responsible for the Portuguese National Program for Patient Safety, as stated in this study. (c) 2022 The Author(s.) Published by S. Karger AG, Basel on behalf of Escola Nacional de Saúde Pública

This is an Open Access article licensed under the Creative Commons Attribution-NonCommercial-4.0 International License (CC BY-NC) (http://www.karger.com/Services/OpenAccessLicense), applicable to the online version of the article only. Usage and distribution for commercial purposes requires written permission.
In another paper, Isabel Jesus Oliveira et al. joined a group of experts to issue recommendations for a high burden disease, stroke: "Best practice recommendations for dysphagia management in stroke patients: a consensus from a Portuguese expert panel."

To finalize the diversity and richness of this issue of the Portuguese Journal of Public Health, we publish two papers about vulnerable populations:

"Risk factors associated with falls among nursing home residents: a case-control study" by Cristina Imaginário et al. and "Tuberculosis and/or HIV infection and associated sociobehavioral factors in immigrants, in Portugal: a cross-sectional, community-based descriptive study" by Rhaisa Farias et al.

Personally, it has been a pleasure to act as co-editor chief along, firstly, with Prof. Joao Pereira and lately with Prof. Antonio Sousa Uva. The support of Dr. Isabel Andrade was also essential. Ending my role in the Journal, I would like to thank them and Prof. Carla Nunes, director of the National School of Public Health and my dearest friend.

I hope that you enjoy this and future issues of the Portuguese Journal of Public Health, submit more and more papers, do more and more excellent research and above all, have a year 2022 full of generosity, wisdom, and peace.

Correspondence to:

Helena Canhão, helena.canhao@nms.unl.pt 